\title{
Race Fucker: \\ representações raciais na pornografia gay*
}

Osmundo Pinho**

\section{Resumo}

Neste estudo, procuro explorar determinada perspectiva crítica relacionada à articulação entre raça, sexualidade e gênero, entendendo que a pornografia gay se prestaria exemplarmente a flagrar a produção de um sistema ordenado de classificações $e$ categorias, estereótipos e representações, instituídos como um discurso capaz de ser lido como o inventário da fetichização socialmente produzida para o desejo sexual racializado. Para desenvolver essa perspectiva apresento uma breve discussão teórica sobre a pornografia, interrogada pela articulação prazer/poder e a leitura de três conjuntos êmicos de representação racial associados ao desejo homossexual: a negritude, a branquidade e a brasilidade.

Palavras-chave: Pornografia, Raça, Gay, Branquidade, Brasilidade, Internet.

" Recebido para publicação 03 de outubro de 2011, aceito em 20 de novembro de 2011. Este ensaio foi originalmente preparado como um apresentação para a "Mesa de Mídia", realizada durante o VII ENUDS (Encontro Nacional Universitário da Diversidade Sexual), realizado em Belém do Pará, entre 9 e 12 de outubro de 2008. Agradeço aos organizadores o convite que me permitiu refletir sobre o tema.

** Professor Adjunto no Centro de Artes, Humanidades e Letras da Universidade Federal do Recôncavo da Bahia, campus de Cachoeira; do Programa de PósGraduação em Ciências Sociais da mesma universidade; e do Programa de PósGraduação em Antropologia Social da Universidade Federal da Bahia. Bolsista do CNPq. osmundopinho@uol.com.br

cadernos pagu (38), janeiro-junho de 2012:159-195. 
Representações raciais na pornografia gay

Race Fucker:

racial representations in gay pornography

\begin{abstract}
In this study the author seeks to explore a specific critical perspective related to the race, sexuality and gender articulation, understanding that gay pornography will be exemplary to show the production of a coordinated system of classifications and categories, stereotypes and representations built as a discourse that may be read as a socially produced inventory of fetichization for racialized sexual desire. In order to develop this view the author presents a short theoretical discussion on pornography, interrogated by the power/pleasure articulation and the reading of three hemic corpora of racial representation related to homosexual desire: blackness, whiteness and brazilianness.
\end{abstract}

Key Words: Pornography, Race, Gay, Whiteness, Brazilianness, Internet. 
Você fica cheio de orgulho e vende os seus abraços em vez de dá-los de graça porque conhece a sua sensualidade. Para que servem, afinal, esses cabelos ondulados com o pente? Para que esse rosto todo maquiado? E para que, além disso, esses olhares insinuantes $e$ lânguidos? Para que o andar ensaiado com arte, e também os passos, a ponto de nem sequer uma vez divergirem da medida dos pés, se não for para exibir a sua beleza, a fim de vendê-la? Petrônio, Satyricon, 62 ou 64 D.C. [tradução: Cláudio Aquati] ${ }^{1}$

Neste ensaio gostaria de dar tratamento um pouco mais sistemático a uma abordagem errática, e construir o sentido político para uma interpretação sobre a pornografia gay disponível na internet. Este estudo me permite explorar determinada perspectiva crítica, relacionada à articulação entre raça, sexualidade, gênero e poder, que busco desenvolver para outros campos ou objetos de investigação (Pinho, 2004; 2005; 2007).

Ora, a pornografia gay ${ }^{2}$ não se prestaria exemplarmente a flagrar a produção de um sistema ordenado de classificações e categorias, estereótipos e representações, instituídos como um discurso dispersivo e flutuante ainda que densamente estruturado (como uma "nuvem"), capaz de ser lido como o inventário da

\footnotetext{
1 Na tradução de Paulo Leminski: "Claro, sabendo a beleza que você tem você a vende, não a aluga. Por que você teria cabelos tão lindamente tratados: Por que esse olhar, esse andar sensual, toda essa gostosura que você demonstra, pra que tudo isso se não está à venda" (1985:152). E no original latino: "Quia nosti venerem tuam, superbiam captas vendisque amplexus, non commodas. Quo enim spectant flexae pectine comae, quo facies medicamine attrita et oculorum quoque mollis petulantia; quo incessus arte compositus et ne vestigia quidem pedum extra mensuram aberrantia, nisi quod formam prostituis ut vendas?".

2 Assumo aqui "gay" como uma categoria êmica, organizadora do índex das perversões de mercado.
} 
Representações raciais na pornografia gay

fetichização socialmente produzida para o desejo sexual racializado? Tomando o repertório pornográfico, ou porção dele, como um fragmento estratificado de uma produção categórica, que discrimina, como a mobilização rizomática de uma máquina classificatória, uma estrutura sempre móvel de categorização. Definindo o exercício sem sujeito de uma lógica classificatória, marcada pelo poder, pelo desejo e pelo paradigma do mercado, forma dominante da representação na sociedade do espetáculo (Debord, 1998).

Buscando desenvolver essa perspectiva, veremos a seguir uma breve discussão teórica sobre a pornografia, interrogada pela articulação prazer/poder; uma apresentação sumária da ambiguidade entre transgressão e normatividade, público $e$ privado, segredo e exposição, que parece estar na raiz do mapa pornô do imaginário gay; uma crítica da forma mercadoria, como modelo sobredeterminante para as políticas categóricas do espetáculo homossexual na internet; e por fim uma leitura de três conjuntos êmicos de representação de conteúdos raciais associados ao desejo homossexual encontrados em sites da internet: a negritude, a branquidade e a brasilidade.

Um desses sites ${ }^{3}$, o MachoFucker, como o nome indica, vende a erótica da transgressão, suscitada pelo sexo gay entre "machos", paradoxo recorrente, e clichê da pornografia (e da erótica) gay, como veremos. O site se propõe a fuder os machos, não apenas por meio da conjunção carnal, literalizando o paradoxo, como representação e como verdade da atuação, base da excitabilidade na pornografia, mas eventualmente, "fudendo"

\footnotetext{
3 Visitamos exaustivamente, na ocasião da apresentação original (2008) e novamente agora (2011), uma série de sites que vendem tempo para assistir filmes gays, ou que permitem baixar filmes ou pequenos clipes (ver a lista ao final). Quase todos são baseados nos Estados Unidos da América, mas vendem o seu produto para o mundo inteiro.

4 Tomando "macho" aqui como uma categoria êmica, como os "machos de verdade", encontrados classicamente em Fry (1982); ver também Braz, em um sentido algo diferente (2007).
} 
também as representações dominantes sobre masculinidade, virilidade, homossexualidade e poder/submissão. O site, ademais, está dedicado a explorar o sexo entre machos na modalidade inter-racial, "fudendo" não apenas a masculinidade, mas também as barreiras e interditos raciais. Fucking race, nesse caso, é ao mesmo tempo a suspensão $e$ a superênfase nas diferenças raciais $e$ nas resistências, corporais e simbólicas, do corpo masculino à penetração e violabilidade. Toda essa teatralização encena assim, no próprio conluio dos corpos, que não poderiam, ou deveriam, imiscuir-se, a violação das identidades auto-idênticas em benefício da circulação das imagens como mercadorias sexuais, como espero poder desenvolver.

\section{Prazer e Poder}

Como Mireille Miller-Young (2008) aponta, poderíamos considerar a indústria pornô tanto como o local de produção de culturas sexuais, como ponto de mobilização do trabalho sexual. Tal como discutido por Maria Elvira Díaz-Benítez (2010) para o caso da indústria brasileira da pornografia, a interseção com o mundo da prostituição ou do trabalho sexual é bem clara. Como produtora de cultura sexual ${ }^{5}$, assim também, a pornografia está atravessada por uma "economia racializada do desejo", como uma forma de "political theater", uma vez que apresenta uma verdadeira fascinação com a diferença racial e suas variações. Se isso é verdade para o caso da pornografia Hip-Hop heterossexual, objeto de análise de Miller-Young, também o é para o nosso caso. Podemos apontar facilmente a produção de categorias ou gêneros racialmente marcados, e mesmo na pornografia brasileira vemos a

\footnotetext{
${ }^{5} \mathrm{Ou}$ o que poderíamos eventualmente qualificar como grades interpretativas, estruturadas como a articulação de temas, tropos, personagens e narrativas modelares, que se prestam a interpretar a experiência, nesse sentido efetivamente produzindo o significado atrelado a leitura da prática, mapa do imaginário, no sentido de decalque de uma topografia erótica e uma planta para mobilização de um agenciamento propriamente sexual.
} 
definição da diferença racial nos filmes explicitamente vendidos como "de negros" ou com negros, ou inter-raciais.

Mas talvez de modo mais significativo seja a pornografia a arena simbólica onde "ideologias socioculturais do desejo e do tabu são postas em cena e manipuladas como normas e categorias que são simultaneamente sustentadas e transgredidas"6 (MillerYoung, 2008:267). Como então uma usina de manipulação de estereótipos e de um erotismo marcado pela diferença racial (assim como por outras), poderia ser considerada como aparelho de produção, marketing e disseminação de categorias da diferença como subgêneros de formas fetichizadas em um teatro político racializado.

A metáfora do teatro político para a compreensão da pornografia como uma plataforma de elaboração e mediação simbólica entre desejo e poder nos permite considerar que a própria estrutura de mercado aberto, no caso dos sites pay-perview que analisamos, funciona como um verdadeiro balcão interativo e multiforme, no qual as dezenas de milhares de acessos moldam, como a mão invisível do mercado sexual, a configuração de um corpus estruturado e rizomicamente complexo (Deleuze \& Guattari, 1996).

A introdução de diferenças raciais, ou de classe, no interior desse aparato representacional, como um sinal invertido da subordinação realmente existente, faz das inferioridades social $e$ política marcas de um atrativo erótico quase irresistível, como se observa para contexto concreto da prática homossexual em diversos quadrantes da América Latina, onde a transgressão do interdito homossexual, parece favorecida pela diferença de classe entre o homossexual de classe média e o jovem heterossexual negro (ou meramente pobre) da periferia ou favela (Rapisardi \& Modarelli, 2001; Giraldo, Arias \& Reyes, 2007). Ora, essa mesma

6 "Social and cultural ideologies of desire and taboo are staged and manipulated, as sexual norms and categories are simultaneously upheld and transgressed." [tradução do autor] 
diferença é erotizada à exaustão nos sites e filmes em questão. $\mathrm{O}$ que é eventualmente vivido, entretanto, como um traço das interações homoeróticas na sociedade de classes, marcada pela colonialidade do poder e pelo racismo, pode ser, no espaço do imaginário pornográfico, manipulado, teatralizado, hiperbolizado, fetichizado livremente ao sabor da navegação errática na web, tal como ele se regula por meio de uma interface de mercado.

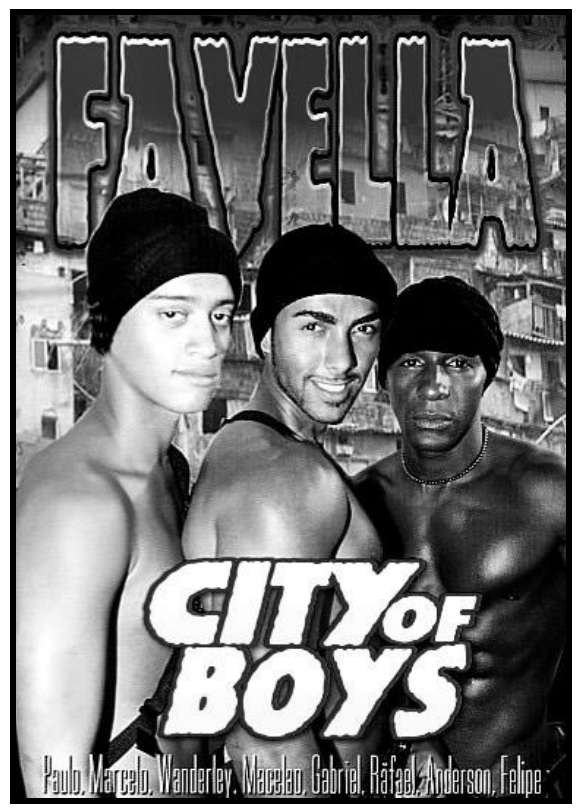

Figura 1: Foto do autor, a partir da capa do DVD.

Ora, as considerações sobre a criação de um sistema, aberto de referências definidas como uma estrutura de acesso nos permitiriam colocar a questão: como a diferença racial é representada no "negócio do desejo" gay? ${ }^{7}$ Como e quais são as

\footnotetext{
7 Perlongher falando sobre o negócio do michê diz que "o fluxo desejante seria capturado pela "máquina de calcular" que "atribui valor aos corpos, remetendoos a um equivalente geral ao mesmo tempo econômico e categorial" (1987:249). Reconheço a analogia e a utilizo para falar do desejo como fluxo abstrato.
} 
suas principais categorias e narrativas-mestras elaboradas? Quais são as imagens dominantes? Que repertórios a coreografia dos corpos masculinos racializados encena no espaço virtualmente ilimitado da representação erotizada na internet? Há, pressupomos, o trabalho de construção ou elaboração coletiva desse imaginário, que sob a aparência de extrema liberdade, organiza as representações em termos de uma categorização racializada do desejo, que figura e dilui relações de poder (dominação/submissão/emulação/narcisismo), teatralizadas como manifestação objetificada do desejo, por meio de sua conversão quase gramatical em uma linguagem erótica, que usa a densidade digitalizada da carne humana como metáfora da diferença sexual/racial. Como questionou Miller: "Como darmos conta das formas por meio das quais o prazer interseciona-se com a política, a identidade e o poder?"8 (Miller-Young, 2008:263).

Vimos, assim como Miller-Young, Díaz-Benítez e outros autores, um interesse qualificado e crítico no modo como as próprias práticas sexuais e suas representações como práticas de poder e produção de hierarquias, poderiam ser consideradas. Desse ponto de vista a pornografia pode ser interrogada como espaço dessa instituição, definido como um mercado para essas representações, e como produtora de determinado conjunto de conhecimento/saber sobre os corpos, que assume, sob a forma mercadoria, o valor de uma verdade sobre o sexo e o desejo, inscrevendo na representação, na condensação dos significados raciais/corporais/sexuais, na imagem da tela, um compêndio, corpus orgânico sempre em crescimento - portanto rizomático (Deleuze \& Guatarri, 1996) - das interações entre poder, desejo e (homo)sexualidade (Díaz-Benítez, 2007).

8 How do we account for the ways in which pleasure intersects with politics, identity, and power? [tradução do autor] 


\section{Transgressão e Interdito}

Consideramos, como outros autores, que em grande medida o fascínio da pornografia reside na simulação do "segredo" revelado, aquilo que deveria estar oculto, off scene, é revelado com riqueza de detalhes, em prolongadas exposições espetacularizadas e devotadas justamente a se submeter ao olhar exterior voyeurístico. $\mathrm{O}$ espectro transgressivo da pornografia se estabelece aí também nesse aspecto de desvendamento ou de exposição de um segredo irresistivelmente terrível que deveria ser mantido oculto. Nesse caso, observaríamos uma medida formal de transgressão de uma convenção social que vê no sexo, não apenas elemento das condutas privadas, mas algo que é perigoso e em certa medida maldito (Barbosa, 1986; Díaz-Benítez, 2010).

Mais além, no caso da pornografia gay, a transgressão tem uma referência objetiva no desafio às convenções sociais reunidas sob o que chamaríamos de "heterossexualidade normativa", implicada na pressuposição de que não só todas as pessoas são heterossexuais, mas também na convicção de que a própria ordem social exige a heterossexualidade. Esta, pensada como princípio dado de sociabilidade, de estrutura social, de autoridade e parentesco, de formação adequada da personalidade e da economia política. O sexo entre homens é, assim, tabu sagrado, apontado como anormalidade, doença, pecado ou desvio. Dessa forma, a homossexualidade afrontaria a ordem social em sua dimensão estrutural mais profunda (Miskolci, 2005, Butler, 2003).

$\mathrm{Na}$ pornografia gay circulada na internet, a transgressão representada pelo sexo homossexual é encenada em uma imensa variedade de posições e situações meticulosamente desenhadas como reprodutoras da violação espetacularizada do tabu. As formas e modalidades padronizadas de tais encenações resultam, entretanto, na conformação de determinados outros padrões e na reprodução ambivalente de elementos da própria ordem social heterossexista que estaria sendo supostamente ultrajada. Assim, é comum nos filmes que analisamos situações de simulação de 
Representações raciais na pornografia gay

hipermasculinidade, como posições que reforçam $e$ ironizam os lugares tradicionais do masculino: policiais, trabalhadores braçais urbanos, dudes, thugs, cholos e hustlers ${ }^{9}$ dos guetos norteamericanos, rapazes da favela brasileiros, e assim por diante. $\mathrm{O}$ potencial transgressivo do sexo gay é assim maximizado na medida em que está anexo ao paradoxo da virilidade sodomizada ritualisticamente e de modo espetacular, para consumo alheio. De modo ainda mais enfático, vê-se nos sites que vendem a simulação do sexo casual e pago com supostos heterossexuais, que são ou enganados, em sites como o Bait Bus, ou sodomizados, em locações que evocam o gueto, como em Thug Hunter. Ou ainda o estilo gonzo, no qual o diretor é também o cameraman, que faz sexo com o performer ao mesmo tempo em que fala com ele e com o presumido consumidor, reforçando,

9 Segundo o Urban Dictionary um Thug é "alguém que vive atrás de confusão, que tem vivido de confusão em confusão e continua vivendo dia após dia sem nada para si. Essa pessoa é um thug. E a vida que ela está vivendo é uma vida de thug". Dudes: "Uma palavra que os norte-americanos usam para dirigirem-se uns aos outros. Principalmente maconheiros, surfistas e skatistas". Cholo: "Cholo é um termo que se refere a homens hispânicos tipicamente vestidos com chinos (calças khakhi), surradas camisetas sem mangas ou camisa quadriculada de flanela abotoada apenas na parte de cima, uma rede para cabelo, ou bandana em volta da testa, usualmente meio sobre os olhos. Cholos com frequência têm tatuagens negras, comumente invocando o imaginário católico, mensagens caligráficas ou nomes de família". E Hustlers: "alguém que sabe como tirar dinheiro dos outros. Vendendo drogas, rolando dadinhos, explorando mulheres. Se virando por dinheiro" [tradução do autor] - "someone who is going through struggles, has gone through struggles, and continues to live day by day with nothing for them. That person is a thug. and the life they are living is the thug life." Dudes: "A word that americans use to address each other. Particularly stoners, surfers and skaters". Cholo: "A cholo is term implying a Hispanic male that typically dresses in chinos (khahki pants), a wifebeater sleeveless teeshirt or a flannel shirt with only the top buttoned, a hairnet, or with a bandana around the forehead, usually halfway down over the eyes. Cholos often have black ink tattoos, commonly involving Catholic imagery, or calligraphy messages or family names". E Hustlers: "someone who knows how to get money from others. selling drugs, rolling dice,pimpin. your hustlin for that money" (http://www.urbandictionary.com/). 
assim, a ilusão de verdade/transgressão. Do mesmo modo, como veremos, do ponto de vista racial os interditos e oclusões do imaginário racial são reforçados e transpostos no sexo inter-racial ou na exaltação da branquidade. É justamente em função disso da superposição sinuosa entre normatividade e transgressão, que parece fundamentar a pornografia em geral $e$, com especial escândalo, a pornografia gay - que podemos falar que estamos diante de:

Uma forma de teatro político onde ideologias sociais $e$ culturais do desejo $e$ do tabu são postas em cena $e$ manipuladas como normas e categorias que são simultaneamente sustentadas e transgredidas ${ }^{10}$ (Miller-Young, 2008: 261-292).

A transgressão domesticada da pornografia gay por meio da produção de categorias de mercado é uma normatização do "desvio" que vibra na exata marcação, mise-en-scène, do "quebrar todas as regras" e "romper todas as barreiras", ${ }^{11}$ simulando, por exemplo, o sexo entre professor e alunos, ou entre o padre e seus pupilos, ou jovens em idade "barely legal", ou ainda o sexo "bareback", sem o uso de preservativos e com ejaculação no interior do corpo dos performers (cream pie). Reforçando ao mesmo tempo valores da masculinidade, como virilidade, forca física, violência e músculos avantajados, o pornógrafo joga todas suas fichas na profanação do ídolo masculino pela dessacralização de seus corpos em poses ensaiadas e longas tomadas explícitas.

As oposições entre público e privado que orientam a regulação de espaços sociais e a transgressão orientada entre eles são propositalmente ultrapassadas no espaço imaginário da

10 "A form of 'political theater' where social and cultural ideologies of desire and taboo are staged and manipulated, as sexual norms and categories are simultaneously upheld and transgressed". [tradução do autor]

${ }^{11}$ Como Parker (1991) descreve elementos centrais da cultura sexual brasileira. 
Representações raciais na pornografia gay

pornografia, como se dessa forma se efetivassem o ultraje e a ilicitude que parecem constituir o princípio erótico da pornografia. As distinções entre público e privado regulam também, de outros modos, "a epistemologia do armário", configurando o segredo como condição fundamental da experiência homossexual e mesmo da experiência do "eu sexual" na vida cotidiana (Sedgick, 2007).

O que aparece na pornografia gay é, entretanto, a própria indiscrição voyeurística como dispositivo organizador do olhar, mas é também evidente que o espaço do erótico só faz sentido contra o pano de fundo mais amplo do "armário", que atualiza o segredo ao recompartimentar a divisão entre o público e o privado. A ilicitude erótica, constituída pela normatividade social, é furiosamente dessacralizada em escala industrial na internet, em meio a uma audiência global e, ao que parece, sempre ávida por penetrar no lado avesso dos paradigmas hegemônicos da sexualidade e do gênero,. Sob a benção do mercado, e assumindo a forma mercadoria, a pornografia pode violentar interditos raciais/sexuais, profanando a oposição público e privado que ganha significado erótico na ambientação da epistemologia do armário (Miskolci, 2009).

\section{O Negócio do Desejo}

Em As Palauras e as Coisas, Michel Foucault (1967) se refere a uma certa "enciclopédia chinesa", descrita em um texto de Borges. ${ }^{12}$ Nela, vemos a enumeração de uma série de seres improváveis. Entretanto, como chama a atenção Foucault, a maior improbabilidade ou estranhamento refere-se ao exotismo

${ }^{12} \mathrm{O}$ texto em questão é O Idioma Analítico de John Wilkins, publicado originalmente em 1952. Nesse conto, ao discutir as dificuldades lógicas de sua "língua universal", Borges se refere a um certo Dr. Kuhn que atribui aos problemas classificatórios discutidos, semelhança com aqueles encontrados em "certa enciclopédia chinesa intitulada Empório Celestial de Conhecimentos Benévolos" ((Borges, 2007:124). 
das categorias empregadas para produção da lista classificatória, que divide os animais em
a)pertencentes ao imperador; b)embalsamados;
c)domesticados, d)leitões, e) sereias, f) fabulosos, g) cães em liberdade, h) incluídos na presente classificação, i) que se agitam como loucos, f)inumeráveis, $k$ ) desenhados com um pincel fino de pelo de camelo, l) et caetera, $\mathrm{m}$ ) que acabam de quebra a bilha, n) que de longe aparecem moscas (Foucault, 1967:3).

Os critérios classificatórios parecem contradizer um ao outro impedindo o leitor de produzir um princípio único que possa organizar a produção de novas classes de animais. Mas, como está apontado, onde tais critérios "podem justapor-se senão no lugar da linguagem?" (id.ib.). Nesse sentido, concordo com Foucault quando assinala que as categorias são produzidas como operadoras de distinções e afastamentos, diferenciações $e$ similitudes produzidas no corpo da linguagem, como uma atividade prática de produção de uma ordem, "um sistema de elementos" que estabelece

os códigos fundamentais de uma cultura - aqueles que regem sua linguagem, os esquemas perceptivos, as suas permutas, as suas técnicas, os seus valores e a hierarquia de suas práticas - fixam logo de entrada para cada homem as ordens empíricas com que terá de lidar e em que se há de se encontrar (id.ib.:8).

Quero sugerir que as categorias que organizam a incrível quantidade de filmes pornôs disponíveis se articulam como uma ordenação que produz critérios de classificação, por meio de uma conversão baseada já no caráter de mercadoria das imagens consumidas; o que aparece literalmente como o valor do erótico, que poderíamos referir ao conteúdo do sexo, como práticas sexuais, representações incorporadas e culturalmente estruturadas 
como valor de uso. Esses diferentes conteúdos, em si tão diferentes e diferencialmente construídos, que resistiriam a uma classificação sistemática, encontram equivalência na forma da imagem em movimento que se vende/compra por dinheiro na internet. $\mathrm{O}$ que regula o seu valor nesse caso é a sua condição de circulação sob a forma mercadoria, que se assume como o que se apresenta como o valor de troca, na dinâmica de substituição da lógica da qualidade pela lógica da quantidade. Ora, como nos diz Baudrillard (1972:181): "É uma astúcia própria da forma velar-se continuamente na evidência dos conteúdos". Assim, a aparente multivariedade dos gêneros $e$ a eroticidade das imagens podem ser reduzidas a um denominador comum que tem sua identidade assegurada por uma condição formal, abstrata. Independentemente dos múltiplos conteúdos representados, a mesma forma pode converter a diversidade substantiva.

No site Adult Entertainment Broadcast Network (AEBN), sediado nos Estados Unidos e fundado em 1999, podemos encontrar mais de 1.000 .000 de filmes, produzidos por mais de 1.500 estúdios. O site conta com mais de 10 milhões de assinantes em todo mundo, utilizando mais de sete idiomas, inclusive o português (Henderson, 2011). A multifária variedade de imagens pode ser adquirida por meio do sistema pay-per-view, no qual o consumidor adquire tempo, entre 15 e 1.000 minutos, variando o preço dos pacotes de tempo entre $\mathrm{R} \$ 6,90$ até $\mathrm{R} \$ 148,00$. Também é possível comprar o filme inteiro e baixá-lo pela internet. $\mathrm{Na}$ página inicial, há um "índice de categorias" que permite buscas por macro categorias: "Lançamentos", "Recém Adicionados", "Os Mais Assistidos", "Estrelas", "Estúdios", "Séries" e "Exclusivo". Mas é possível uma busca mais sofisticada, temática, por meio de 81 categorias, apresentadas na tabela abaixo 


\begin{tabular}{|l|l|l|}
\hline Afeitando & Cream Pies & Namorados \\
\hline Alt (alternativo) & Câmera escondida & Negros \\
\hline Alta Definição & DILF - Pais Apetitosos & Orgias \\
\hline Amadores & De Três & Paródia \\
\hline Anal & De uniforme & Penetração dupla \\
\hline Ao ar livre & Ejaculação & Penetração extrema \\
\hline Apanhando & Europeus & Policiais \\
\hline Aparentando não ser gay & Fetish & Porcos \\
\hline Asian, Asiático & Gang Bang & Porno Duro \\
\hline Auto-Fellatio & Garotos atléticos & Pornô suave \\
\hline Award Winning Movies & Gordinhos & Pre-Camisinha \\
\hline BDSM & Hetero para gay & Punição \\
\hline Bissexuais & Homens Musculosos & Pés \\
\hline Boquetes & Homens peludos & Pênis grandes \\
\hline Brasileiro & Instrucional & Rufião \\
\hline Britânicas & Inter-raciais & Russo \\
\hline Bundonas & Internacionais & Sem camisinha \\
\hline Buraco de gloria & Lançamentos & Sem circuncidar \\
\hline Cabeças raspadas & Latinos & Sexo Prisional \\
\hline Característica & Luta corpo a corpo & Sexo Seguro \\
\hline Cascata dourada & Maduras & Tcheco \\
\hline Clássico & Massagem & Twink \\
\hline Colarinho Azul & Masturbação & Universitários \\
\hline Colarinho Branco & Militares & Unmosaic Japonês \\
\hline Consolador & Modelo & Vintage \\
\hline Couro & Mosaic Japonês & Voyeurs \\
\hline Cowboys & Músculos & Compilação \\
\hline & &
\end{tabular}

Como Nestor Perlongher discute, e podemos observar aqui, a relação entre o "fluxo desejante" e a "máquina de calcular", produz uma intensa proliferação categorial: "as diferenças de valor remetem a um sistema de nomenclaturas, estas por sua vez proliferantes" (Perlongher, 1987:249). É interessante perceber que a abstração chegou a sua forma máxima nessa locação do negócio do desejo. Porque não há diferenças de valor entre as categorias, a única medida de conversão universal é o tempo, diferentemente do que aconteceria na modalidade menos "racionalizada" do negócio do desejo que o autor descreveu (id.ib.). O prefácio de Eliane Robert de Morares (2008) ao "Saló" de Sade enfatiza como 
Representações raciais na pornografia gay

o aspecto numerário e a proliferação combinatória que estrutura a lista de perversões do livro parecem ter a forma própria da definição da eroticidade, e como essa parece ser justamente a intuição genial e mais transgressiva da criatividade de Sade.

O intento combinatório implica uma recusa frontal ao sentimento amoroso, já que sua realização tem por base a indiferenciação entre os sujeitos, a substituição de uns pelos outros, a intercambialidade dos corpos (id.ib.:11).

Aí está a grande sabedoria devassa de Sade, e na qual faz residir a sua "filosofia lúbrica", "que reconcilia a abstração aritmética com a irredutível imanência do corpo" (id.ib.:12). Assim, na pornografia os corpos são intercambiáveis - como valor erótico - e se trocam como moeda, pelo seu valor abstrato.

Parece agora claro que natureza de mercadoria das imagens disponíveis demanda, obriga, a uma classificação que permita à navegação rápida e exitosa dos consumidores. Desse ponto de vista, a estrutura do mercado - baseada na dualidade entre o conteúdo como valor de uso e a interface de circulação que converte as imagens em pura quantidade, como valor de troca, opera como a estrutura das próprias variedades hiper-abundantes do desejo homossexual. O domínio do erótico surge assim como o sistema dos objetos (sexuais), que copia do mercado sua forma estrutural dada. De tal sorte que a estrutura do desejo é replicada como a estrutura do consumo:

O consumo não é uma prática material, nem uma fenomenologia da abundância, não se define nem pelo alimento que se digere, nem pelo vestuário que se veste, nem pelo carro que se usa, nem pela substância oral $e$ visual das imagens e mensagens, mas pela organização de tudo isto em substância significante (Baudrillard, 1989:206).

E justamente a organização da substância significante, sob a forma mercadoria, que é produzida pela internet como mercado, 
dada a condição tecnológica de reprodução da imagem e do som, alicerce fundamental para a própria indústria cultural (inclusive pornô), do simulacro e da ideologia generalizada como princípio simbólico da sociedade e da organização do simbólico ele mesmo, como insistem os frankfurtianos (Adorno, 1991; Adorno \& Horkheimer,1997; Benjamim, 1996). Sob essa ótica, a condição de produção seriada de imagens coloca em novas bases a percepção cultural, a consciência estética e o papel da tradição nas sociedades modernas. Por outro lado, inscreve a arte no domínio da produção em escala. Os filmes - ou outros "produtos culturais" - são possíveis economicamente porque são reproduzíveis e são reproduzidos por que se pagam economicamente na escala da quantidade, que se sobrepõe a qualidade. Aqui a relação dialética entre quantidade e qualidade estabelece-se como o fulcro da questão. ${ }^{13}$

A lógica das estruturas significantes define e recorta o campo de objetificações possíveis do real, como, aliás, tem sido repetido e consistentemente apontado pela etnografia, que nos mostra como as sociedades produzem as categorias de entendimento do real como as categorias de produção da própria realidade significativa (Sahlins, 2001). Assim é que a representação da sexualidade, como o trabalho de imobilizar-se o significado em tipos como imagens de uma presença objetiva, participa das formas de sua reprodução, não da forma ingênua imaginada por alguns, mas porque representar a sexualidade é representar o vínculo, ou elo contingente, entre superfícies de sentido e determinados conteúdos - já significantes significados - como uma interioridade ou verdade, atribuindo-se ao já representado um caráter de realidade substancializada.

Diante disso, contemplamos a modalidade de consumo da pornografia gay como posta em ação pela fixação de signos-

${ }^{13}$ Andy Warhol é o artista moderno que teria capturado com maior intensidade a relação contraditória entre quantidade e qualidade constitutiva da mercadoria como base do sistema capitalista de produção, tendo inclusive produzido algumas imagens que consideraríamos pornográficas (Jameson, 1984; Honnef, 1992). 
Representações raciais na pornografia gay

mercadoria ou imagens-mercadoria (Baudrillard, 1972). A sexualização ou erotização dessas imagens-mercadoria já se realiza, no espaço definido pelas condicionantes estruturais, como mercadoria. E como economia do desejo, o sexo racializado pode encontrar assim o circuito de consumo global de imagens encarnadas em corpos racializados/étnicos. Como forma acabada da lógica classificatória, produz assim autonomamente o sistema de classificação de uma economia política da sexualidade, baseada na circulação de significados, corpos e valores.

\section{Thugxploitation: a violação da masculinidade negra}

Dentre as categorias de navegação no site AEBN, encontramos diversas que poderiam ser consideradas racializadas: asiáticos, negros, europeus, brasileiros, inter-racial, rufião (thug, no original em inglês), latino, russo e tcheco. Há algumas categorias nacionais, mas que expressam, na verdade, uma identificação no corpo, como veremos para o caso brasileiro, e assim também para russos e tchecos - que em outros sites aparecem como "rapazes do leste europeu", famosos pela beleza "clássica", e pela sensibilidade bissexual. De uma maneira ou de outra, a pornografia não parece estar alheia, nessa instância de produção categorial, ao agenciamento de representações raciais. Cito mais uma vez Néstor Perlongher:

O desejo, lançado em circulação através do dinheiro (pensado aqui como fluxo de intensificação, e não somente como signo 'racional'), carrega, para se excitar, oposições sociais que fraturam profundamente (historicamente) $\mathrm{o}$ corpo social (1987:256).

No caso dos negros, a conexão entre raça e sexualidade está bem enraizada e tem sido bem discutida por inúmeros autores. ${ }^{14}$ $\mathrm{Na}$ excelente coletânea de poesia pornográfica organizada por

${ }^{14}$ Como faz, por exemplo, Corrêa, 1996, e recentemente, Moutinho, 2004. 
Alexei Bueno, encontramos diversos exemplos dos séculos XVI, XVII e XVIII que associam, em escala secular, negritude $e$ africanidade à desmesura sexual representada em falos descomunais, nas comparações com animais, na compulsividade sexual, na extrema objetificação, etc. (Bueno, 2004). Considerando que, como aponta o autor na introdução, "o corpus da poesia pornográfica em cada língua é como a ponta do iceberg" (id.ib.:9), poderíamos dizer que as representações da sexualidade transgressiva têm estado de longa data conectadas à racialização. Os versos de Gregório de Matos, por exemplo, são bem conhecidos por se referir à vida sexual (e ao sexo inter-racial) do Brasil colonial, mas há também interessantes exemplos encontrados em Bocage (1765-1805), autor arquiclássico da tradição pornográfica, que conta as aventuras do "Preto Ribeiro", "preto na cara, e enorme no mangalho", ou na incrivel história da "puta" Manteigui e sua paixão por "um cafre infame":

"Mete mais, mete mais" (ia dizendo)

A marafona, ao bruto, que suava,

E convulso fazia estrondo horrendo

Pelo rústico som com que fungava

"Mete mais, mete mais que estou morrendo!..."

"Mim não tem mais" O negro lhe tornava;

E triste exclamava a bêbada fodida:

"Não há gosto perfeito nesta vida".

K. Mercer e Isaac Julian (1988) em texto célebre discutem a conexão entre raça, política sexual e masculinidade no espaço da globalização anglo-saxã. ${ }^{15}$ Os autores apontam para a biologização da negritude como instância definidora de sua hipersexualização (id.ib.:134). Ocorre, como ainda apontam, que muitos homens negros performam com entusiasmo os estereótipos sexuais ligados à violência que se esperam deles, como também discute Bell Hooks (2004). Na produção de imagens para o cinema

${ }^{15}$ Ver também o trabalho de Alexander (2000). 
Representações raciais na pornografia gay

brasileiro, veríamos, do mesmo modo, uma reprodução das contradições da racialização e sexualização de sujeitos negros. ${ }^{16}$ Os autores chamam ainda a atenção para a fetichização/decomposição do corpo negro, o que, certamente, no caso da pornografia atinge sofisticação estupefaciente, com as cenas de cream pie, dupla penetração, bareback, gang-bang, fisting, etc. De tal forma que:

O corpo-inteiro é fragmentado em micro-detalhes - peito, nádegas, braços, pênis, costas - incitando a dissecção escopofílica das partes que compõem o todo. Como num talismã, cada parte é, por meio disso, investida do poder imaginário para criar o conjunto místico da sexualidade negra na fantasia colonial (Mercer and Julian, 1988:148). ${ }^{17}$

Os filmes e cenas consideradas, não só exploram até a exaustão tal fragmentação - como de resto faz toda pornografia mas elegem como matéria dessa fragmentação vetores de decomposição associados ao folclore sexual urbano sobre os negros. Assim, encontramos uma série de filme sobre a vida no gueto ou "in da hood". Filmes que contêm palavras como gangstas, hustlers ou thug no título, e performam o imaginário do "rufião", bandido, "cholo", ou semimarginal do gueto. Há uma série de numerosíssimos títulos que remetem a uma espécie de blaxploitation, espetacularizando componentes da vida social negra como a ornamentação para circunscrição erotizada do homem negro. ${ }^{18}$ Ora, a consciência da analogia parece ser tal, que

\footnotetext{
${ }^{16}$ Conferir, por exemplo, Rodrigues (2001), que é, em alguma medida, contrariado por abordagens mais recentes, como a de Miller-Young já citada (2008).

${ }^{17}$ The body-whole is fragmented into micro -details - chest, buttocks, arms, pennies, torso - inviting a scopophilic dissection of the parts that made the whole. Like a talisman, each part is thereby invested with the imaginary power to summon up the whole 'mystique' of black sexuality in colonial fantasy. [tradução do autor]

${ }^{18} \mathrm{O}$ gênero conhecido blaxploitation lançado nos anos 70, teria o filme Shaft, dirigido em 1971 por Gordon Parks, como símbolo máximo, e explora a vida no
} 
mesmo um título parodia explicitamente o gênero com o título irônico de "thugxploitation".

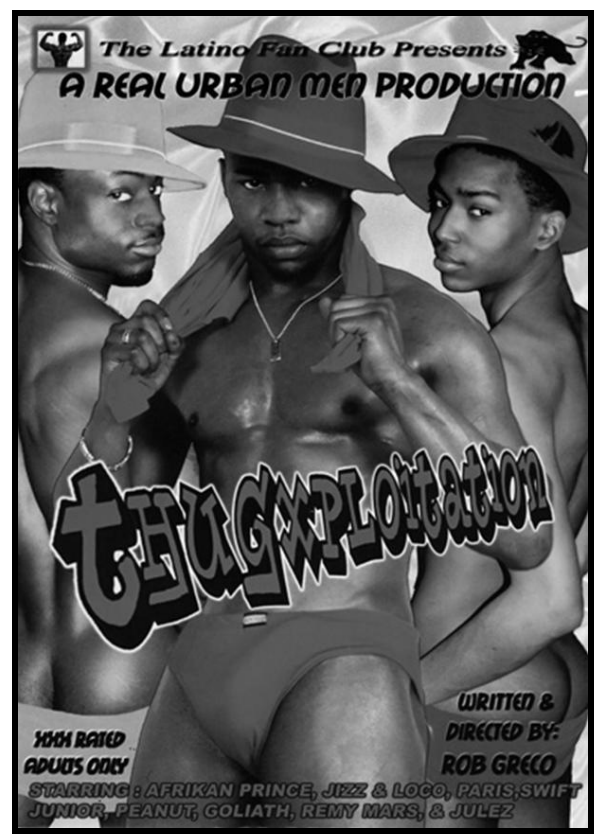

Figura 2: Foto do autor, a partir da capa do DVD.

Nesse caso, como em outros, o que parece ser a confirmação dos estereótipos torna mais clara e facilmente decodificável a eroticidade. O já referido site Thug Hunter explora as aventuras de garotos brancos, que encontram thugs dispostos a sexo por dinheiro em regiões de aparência degradada. Toda a teatralização das hierarquias raciais é sexualizada e erotizada aqui, uma vez que na quase totalidade das cenas, o rapaz branco assume a postura de ativo sexual, sendo agraciado com longas

gueto com negros como heróis e em situações de disputa entre bandidos, traficantes de drogas e policiais brancos corruptos. 
sessões de sexo oral, em seguida sodomizando o thug em troca de algumas centenas de dólares. Invariavelmente os diálogos antes da cena sexual, que simula ser completamente espontânea, envolvem perguntas sobre a romanceada e pregressa vida no crime do thug e sobre o sexo na cadeia, outro fetiche regular.

As políticas sexuais/raciais que vemos teatralizadas no espaço imaginário da pornografia gay mobilizariam parâmetros para uma plataforma de repetição/reprodução de imagens $e$ estereótipos, e como estamos insistindo, como máquina produtora de uma categorizada experiência do erótico, permeada por representações de poder/saber/desejo (Collins, 2005:52). Como tem sido apontado, por outro lado, a diferenciação dos corpos e sua hierarquização colonial demandaram a regulação de corpos sexuados e racializados, justamente por meio de dispositivos de racialização e sexualização; ${ }^{19}$ um modo para proceder-se a distinção entre selvagens (negros, índios e mestiços) e civilizados, "metáfora constitutiva do sistema colonial latino-americano" (Figari, 2007). O homem branco heterossexual colonizador ocupou o lugar discursivo do macho penetrador e civilizador, ativo sexualmente e produtor de história e cultura, reservando para negros, índios, mulheres e "pervertidos" sexuais, o lugar passivo de objeto da dominação e do disciplinamento, e o lugar da sexualidade indomável, abjeta e perigosa (Figari, 2007; Young, 2002). No espaço pós-colonial das culturas latino-americanas, as marcas de sua ambivalência e a permanência da colonialidade do poder não podem ser contornadas. Desse modo, as representações sobre a alteridade cultural "latina" portam as marcas de racializacão e colonização, e não é por acaso muitos filmes negros incluírem latinos e vice-versa, e haver mesmo um gênero conhecido como "Blatino", com performers afroamericanos, latinos e afro-latinos: papithugz. ${ }^{20}$

${ }^{19}$ Como discutiu já classicamente para o caso da mulata brasileira Mariza Corrêa, (1996).

${ }^{20}$ Diversos sites como <http://bilatinmen.com/>, <http://papithugz.com/>, $<$ http://blatinostuds.com/ >, exploram esse "filão". 


\section{Branquidade: “fudendo" o sublime}

Ainda que nunca tenha encontrado um filme que faça explícita menção à branquidade dos performers ${ }^{21}$, diversos estúdios especializaram-se em filmes com garotos do "leste europeu" e/ou tchecos. Bel Ami, talvez o mais famoso deles, em seus mais de 40 filmes, jamais apresentou com performers negros, asiáticos ou latinos. ${ }^{22}$ Do mesmo modo, em seu site não há nenhuma referência explícita à branquidade, mas aos ambientes idílicos das locações em regiões campestres da Europa, nas praias de Portugal, ou mesmo na África do Sul. A ênfase dos diretores parece ser na pureza, inocência, e no aspecto juvenil e algo distraído dos performers, que transitam de brincadeiras quase infantis, como guerras de travesseiros, a cenas apaixonadas de sexo explícito, maximizadas ademais pelo caráter ambíguo da identidade sexual dos atores, ressaltando a virilidade delicada de jovens garotos de aparência burguesa. Não é preciso, aliás, muito esforço imaginativo para perceber como no Brasil, ou em outros países multirraciais - nos quais, via de regra, vigoram hierarquias raciais -, a representação desses corpos racialmente imaculados, dos doces olhos azuis e da aparência de meninos bons e bem nascidos é associada às representações vigentes sobre os paradigmas corporais de raça e classe (Pinho, 2006; Omi \& Winant, 1994; Dijk, 2008).

$\mathrm{Na}$ tradição ocidental, a branquidade imaculada permanece como indicador de pertencimento étnico/racial, de uma genealogia de família ou de um pertencimento de classe, sendo metáfora de poder duradouro e do sublime erótico. ${ }^{23}$ A representação da

\footnotetext{
${ }^{21}$ Com exceção dos filmes com alusões ao nazismo ou à subcultura skinhead, ou, o que é muito significativo, filmes de caráter "inter-racial", tanto brasileiros, como "internacionais", com títulos como: Black dicks in may White ass ou White Nynpho, este último de um estúdio brasileiro e com elenco brasileiro.

$22 \mathrm{http}$ ://tour.belamionline.com/free.aspx

${ }^{23}$ Recentemente um pequeno escândalo repercutiu nas redes sociais a partir de Salvador. Um conhecido produtor de festas gay de grande sucesso teria ofendido
} 
Representações raciais na pornografia gay

beleza pálida das musas românticas do século XIX ou fetichismo da branquidade ligado a apresentadoras de programas infantis são instâncias dessa configuração no Brasil, como sabemos (Sovik, 2004). O "poder duradouro da branquidade" resiste, todavia, ao permanecer reluzentemente oculto pelo status hegemônico, de tal modo que as outras "raças" devem ser marcadas como étnicas ou figurativamente racializadas. A branquidade e o mito de sua identidade "não marcada" extrairiam justamente dessa sua inarticulação, notadamente no ambiente ideologizado pela miscigenação no Brasil, seu poder na vida social ordinária (Ware, 2004; Frankenberg, 2004). No espaço imaginário da pornografia gay, a branquidade, ainda que não exatamente articulada em termos discursivos, é uma representação poderosa.

Do ponto de vista de uma política vernácula, o corpo branco é a personificação de uma hegemonia encarnada, algo análogo ao que apontou Shery Ortner (2007) para o "homem Davos": "sem dúvida há sujeitos culturais que totalmente incorporam, na forma de poder, a cultura dominante". Mas no espaço das representações homoeróticas, a branquidade,

um interlocutor em uma rede social na internet. $\mathrm{O}$ interlocutor, que seria negro, ao que parece referiu-se ao fato de estudar fora do país, ao que o produtor assim respondeu: "Eu sei muito bem quais são seus estudos aí... Puta aqui é vc, que faz prostituição... esse é seu estudo, vc já viu preto estudar fora do país? Se toca, preto, brasileiro e baiano, nordestino..." (...) "Apesar de por ter tudo pela minha família que tem um histórico positivo na sociedade baiana... já a sua deve ter um histórico de senzala em algum interior da Bahia... (...) Se toca man, vc vai nadar, nadar e morre na praia... Vc é um nada, e mesmo que consiga chegar em algum lugar... Sempre vai ser diferente.. em qualquer espaço... Vc sabe pq né? Sua cor oferece uma coisa de boa... a genética física... todo pretinho tem um corpinho gostoso... Fora isso, fedem mais que qualquer ser humano". (http://porrasalvador.tumblr.com/). Além do extremismo das colocações, chama a atenção o fato de que seu autor mobiliza um repertório racista sobre origem social, classe, raça e sexualidade que nos permitiria ao menos flagrar alguns elementos que comporiam a cena de recepção de imagens de sublime erótico encarnado pela branquidade em um contexto como o brasileiro, ou talvez baiano, no qual "os pretinhos tem um corpinho gostoso", mas "tem um histórico de senzala", sem contradição aparente. 
notadamente quando associada à inocência da juventude, a locações com luz natural em espaço aberto, em meio a campos de flores e lençóis de seda em tons pastéis, remete a um ideal de pureza sublimada. A hegemonia política da branquidade na esfera do "mundo vida" encontra uma representação purificada na forma de jovens rapazes imberbes, garotos bonitos (pretty boys), que não compartilham nada com thugs e cholos dos filmes negros ou latinos, muito menos com os "machos de verdade" dos filmes com temas brasileiros que veremos a seguir. A incorporação pornográfica dos ideais de branquidade inventa assim um sublime erótico gay.

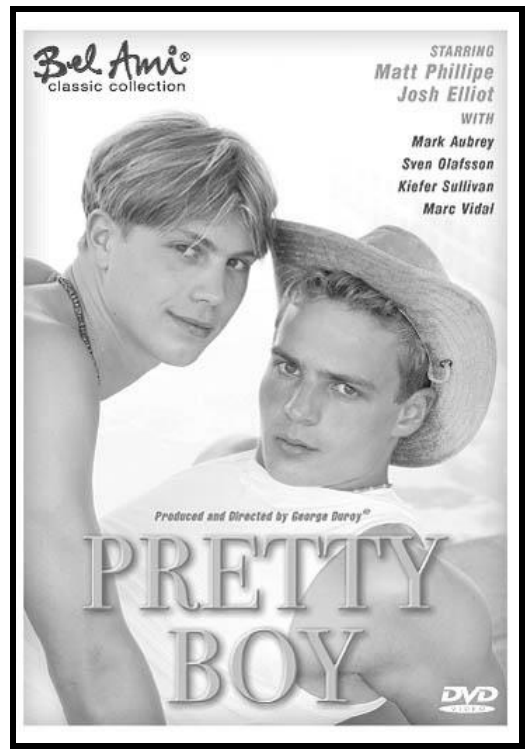

Figura 3: Foto do autor, a partir da capa do DVD.

A pureza (racial) dos corpos juvenis pode assim encarnar o ideal de uma verdade (estética) inquestionada, remetida aos cânones ocidentais clássicos, como o Apolo de Belvedere, ou o Davi de Michelangelo, incorporando a um só tempo um ideal 
civilizatório racializado e a transparência de uma verdade eterna, ligada ao sublime estético. Contra a história colonial de miscigenação e justaposição étnica, e de transgressão rumo extratos inferiores da sociedade, temos também uma história de identificação com ideais eróticos da civilização.

Assim, contemplamos o corpo branco, sempre presente $e$ reapresentado, luminoso em sua verdade, loura e transcendente. A branquidade em sua pele é signo de pureza, e da pureza da verdade que nos traz, inviolável, sua presença mistificada. Um ideal de beleza que representa uma beleza ideal. Ora, o ideal ao permanecer inviolável é sacrificado em rituais corporais laicizados e espetacularizados ao extremo, encenados, como apontei, em uma ambiência de pureza e transcendência, sendo os corpos brancos solene e literalmente "fudidos" em posições acrobáticas, em orgias ou cenas românticas a dois, mas milimetricamente dissecados e também fetichizados como os corpos negros, mas, nesse caso, a natureza da transgressão parece ser outra.

$\mathrm{O}$ aspecto transgressivo da pornografia que já foi ressaltado aparece aqui como uma violação do sublime da branquidade, ou seja, o caráter de pureza, beleza, ideal, e verdade, é submetido ao processamento voyeurístico da máquina produtora de categorias sexuais homossexuais. Fetichizando objetos culturais-sexuais (imagens-mercadorias), o pornógrafo segue "fudendo" o sublime.

\section{Brasilidade: o "macho de verdade" como "puta"}

Não se restringe ao espaço da pornografia gay na internet o trabalho de imaginação do Brasil como uma sociedade e uma cultura sexualmente permissivas e, mais que isso, identificadas com as próprias fontes de liberação e desmedida do desejo. A auto-identidade brasileira tem sido construída por meios vernáculos ou eruditos em torno da sexualidade, do desejo, do hedonismo corporal, do culto ao prazer, da beleza e do irrefreamento sexual, do qual o Rio de Janeiro é o exemplo máximo (Goldenberg 2002, Figari, 2007). Desde as descrições que 
aparecem reunidas, por exemplo, no livro de João Silvério Trevisan, "Devassos no Paraíso" (1986), passando obviamente pela elaboração sócio-antropológica que lhes dá Gilberto Freyre, a sexualidade, a sensualidade e o Brasil se nos apresentam como todo um repertório de conexões entre identidade nacional, sexualidade e poder (Trevisan, 1986; Freyre, 1992[1933]). Mais recentemente, Richard Parker e Carlos Figari reconstituem essa historiografia das sexualidades (neo)coloniais no Brasil (Parker, 1991; 2002; Figari, 2007). O próprio Gregório de Mattos, já referido, ainda ano século XVII, refere-se à devassidão persistente $e$ perniciosa, que seduzia a todos e mergulhava a cidade da Bahia em um pântano de imoralidade, corrupção e prazeres ilegítimos:
"Se de dous ff composta
Está a nossa Bahia
Errada a ortografia
A grande dano está posta:
Eu quero fazer uma aposta,
E quero um tostão perder,
Que isso há de perverter,
Se o furtar e o foder bem
Não são os ff que tem
Esta cidade a meu ver".

Essa auto-imagem de devassidão é ainda reforçada pela retórica da nacionalidade que enxerga no dispositivo sexual da miscigenação racial o fundamento da nacionalidade. ${ }^{24}$ Assim, na narrativa de origem do sentimento nacional, como aparece em Freyre e em inúmeros outros de seus seguidores, o ato sexual, e o desejo inter-racial, formariam o núcleo duro da nacionalidade. A própria sexualidade dos brasileiros é o aspecto instituinte da nacionalidade, no ambiente hierárquico e desigual definido pela

\footnotetext{
${ }^{24}$ Interessante perceber como esse conjunto de representações aparece, por exemplo, no contexto da indústria do sexo transnacional, como discute Adriana Piscitelli (2009) com relação às trabalhadoras sexuais brasileiras na Espanha.
} 
engrenagem econômica da vida social no Brasil colônia. Articulando, na história (e na economia política), e não meramente nas representações, sexo, raça e poder (Freyre, 1992; 2000).

Alguns autores identificam nessa articulação uma espécie de orientalismo, que sob uma ótica brasilianista enxerga no exotismo erótico a particularidade sexual/cultural no Brasil, e sobre-enfatiza a dimensão econômica da sexualidade de matriz colonial. Como Carrara e Simões (2007), que criticam trabalho recente do antropólogo norte-americano Richard Parker (2002). Desse ponto de vista, a oposição já clássica, descrita por Peter Fry (1982), entre modos de sociabilidade e sexualidade, igualitários ou "modernos", referidos a fragmentos específicos de classe no Brasil, não poderia ser usada para denunciar um "atraso" relativo do Brasil, ou de seus setores populares, em relação à modernidade ou à democracia sexual "moderna".

No espaço imaginário da pornografia gay na internet, esse tema volta à cena. Já há alguns anos, estúdios como o AMG Brasil e o Alexander Pictures têm produzido no Brasil, com performers brasileiros, filmes supostamente voltados para um público internacional ou norte-americano. Os diretores e os recursos são norte-americanos, mas a matéria-prima (ou suporte material) do desejo representado, baseia-se na encarnação erotizada de uma imagem de brasilidade que, se o olhar norte-americano parece reconhecer, a própria "cultura sexual" brasileira parece consolidar.

Fundamentalmente, nessa eroticidade se encontra uma ambiguidade que enfatiza a carnavalização das regras $e$ hierarquias que se oporiam a uma cartografia mais clara, simétrica, "ocidental" ou "moderna", em que reencontramos o tema do orientalismo sexual. A linha de cor seria supostamente inexistente no Brasil, assim como uma linha (fronteira) sexual, que separaria de modo irredutivel homossexuais e heterossexuais. A ambiguidade racial/sexual brasileira incorpora-se assim na figura mestiça. Tal ambiguidade racial aparece em Freyre já associada à determinada ambiguidade sexual, e o mestiço "homem de meia raça", é também o "homem de meio sexo" afeminado e com 
modos de mulher. Ainda seguindo Freyre, a condição transitiva do mestiço equivale à falta de lugar, ou inadequação subjetiva, também encontrada entre os homossexuais (1992). De outro ponto vista, a hiperexcitação do português, elemento explicativo no argumento de Freyre, autoriza uma hipervirilidade branca, identificada com a posição do colonizador-civilizador, assim como a da raça que se dirigia a outros objetos apassivados, mulheres brancas, escravas e escravos, como mais uma vez Freyre descreve proustianamente. ${ }^{25}$ Nesse sentido, como revela Cesar Braga-Pinto (2006), há uma conexão estreita entre a bissexualidade Freyreana, do ponto de vista de uma lógica explicativa, e o aspecto transacional da sexualidade como dispositivo de poder, orientado pela oposição atividade/passividade.

Fry (1987) mostra a instabilidade e o aspecto performático das identidades sexuais masculinas no contexto periférico de Belém do Pará nos anos 70. O "homem de verdade" se comporta socialmente como homem e nunca "dá", ou seja, permite-se ser passivo numa relação sexual. De tal modo, que o mais importante para a definição da masculinidade heterossexual, não seria tanto o parceiro sexual, mas o desempenho particular dos parceiros vis-àvis. E, mais interessante, ao que parece os parceiros sexuais ideais preferidos das "bichas" seriam os "homens de verdade" (id.ib.:87). Será essa configuração que aparecerá tematizada como eroticidade no imaginário pornô associada à brasilidade. $\mathrm{O}$ aspecto carnavalizante da sexualidade brasileira, em que tudo é permitido, e o que pareceria improvável do ponto de vista das oposições sexuais rigidamente heteronormativas aparecem incorporados nos ambivalentes corpos morenos e "safados" dos rapazes brasileiros.

Tal ambiguidade sexual-racial, como sabemos, não é exclusiva do Brasil e reaparece em diversos contextos etnográficos da América Latina: na Argentina, no Peru, na Colômbia, etc.

\footnotetext{
${ }^{25}$ Ver o trabalho de Helena Bocayuva (2001) sobre o intercâmbio de categorias raciais e de gênero em Freyre.
} 
(Giraldo, Arias \& Reis, 2007; Fernández-Dávila, Percy et alii, 2007; Rapisardi \& Modaralli, 2001). Um dos aspectos mais intrigantes, do ponto de vista sociológico, tem a ver com a natureza de classe do trânsito que fazem rapazes pobres ou negros da periferia em direção a relacionamento com homens gays de classe média. A mobilização das estratégias de poder aparece aí de modo algo contraditório, porque a situação de gênero coloca os jovens heterossexuais na posição dominante, mas a situação de classe os coloca em posição (ou os recruta a partir de uma posição) de subalternidade. Assim o cruzamento das hierarquias $e$ desigualdades parece produzir um efeito algo paradoxal, que se resolve no ato sexual. E é justamente esse ato sexual transgressor/inversor das hierarquias (homo)sexuais que é espetacularizado no pornô gay "brasileiro".

No corpus que discutimos anteriormente, a pureza racial e a verdade da beleza, incorporadas no corpo de jovens efebos de olhos azuis, são a dessacralização pervertida no ato transgressivo pornô. Nesse caso, o que parece estar no centro, coração palpitante da transgressão pornô, é a própria ideia de masculinidade e/ou de virilidade, gráfica e ideologicamente estabilizada na oposição passividade/atividade sexual. Porque os jovens "machos de verdade" brasileiros que aparecem nos filmes são alçados a condição de ícones do desejo gay transgressivo na medida em que são justamente "machos" tornados "putas". 


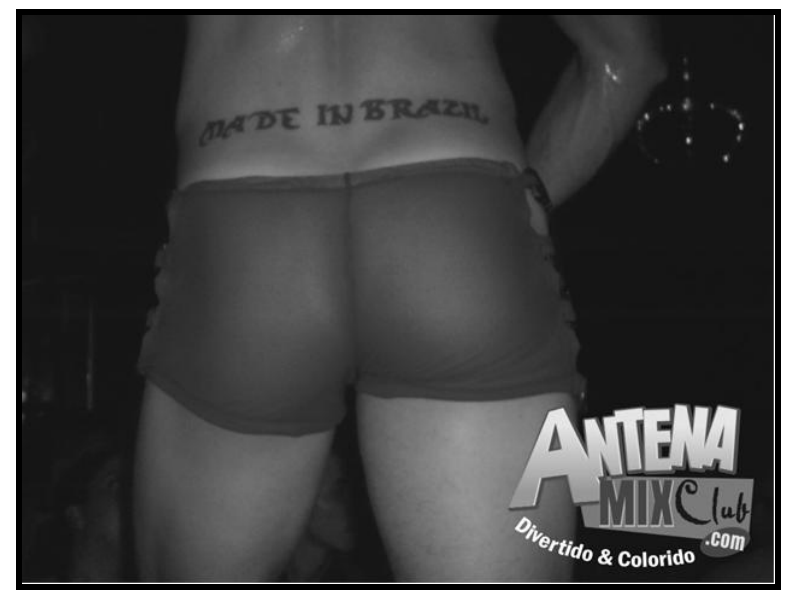

Figura 4: Foto do autor, a partir do site Antena Mix.

Maria Elvira Díaz-Benítez (2010) aponta, assim como outros autores, para a importância da "bunda" no imaginário sexual brasileiro. Nesse caso, o tropo da bunda e do sexo anal incorporase à gramática das sexualidades pornô como a própria representação da brasilidade $e$ de uma masculinidade desconcertante, porque justamente subvertida na medida de sua violação. A bunda masculina nesse caso aparece como significante de um interdito, que sacrificada no altar espetacular da pornografia, pode converter "machos de verdade" em "putas", para o deleite voyeurístico de audiências anônimas.

\section{Referências bibliográficas}

ADORNO, T. O Fetichismo na Música e a Regressão da Audição. In: Adorno, T. Os Pensadores. Horkheimer - Adorno. São Paulo, Nova Cultural, 1991, pp.79-106.

ADORNO, T. \& HORKHEIMER, M. A Indústria Cultural: O Esclarecimento como Mistificação das Massas. In: AdORNO, T. \& HORKHEIMER, M. 
Representações raciais na pornografia gay

Dialética do Esclarecimento. Rio de Janeiro, Jorge Zahar, 1997, pp.113-156.

AlEXANDER, Claire. Black Masculinity. In: AlEXANDER, Claire; OwUSU, Kwesi. Black British Culture and Society. A text Reader. London and New York, Routledge, 2000, pp.373-384.

Barbosa, Gustavo. Grafitos de Banheiro. A Literatura Proibida. Rio de Janeiro, Editora Ânima, 1986.

BAUdRILLARD, Jean. O Sistema dos Objetos. São Paulo, Perspectiva, 1989. . Para Uma Crítica da Economia Política do Signo. São Paulo, Martins Fontes, 1972.

Benjamin, Walter. A Obra de Arte na Era de Sua Reprodutibilidade Técnica. In: BENJAMIN, Walter. Magia e Técnica, Arte e Política. Ensaios sobre literatura e história da cultura. Obras Escolhidas, vol. 1. São Paulo, Brasiliense, 1996, pp.165-196.

BocayUVA, Helena. Erotismo à Brasileira. O Excesso Sexual na Obra de Gilberto Freyre. Rio de Janeiro, Garamond Universitária, 2001.

BORGES, Jorge L. O Idioma Analítico de John Wilkins. In: BORGES, Jorge L. Outras Inquisições (1952). São Paulo, Companhia das Letras, 2007, pp.121-126.

BRAGA-PINTO, César. Os "desvios" de Gilberto Freyre. Novos Estudos, $\mathrm{n}^{\circ}$ 76, São Paulo, CEBRAP, nov. 2006, pp.281-288.

BRAz, Camilo Albuquerque de. Macho versus Macho: um olhar antropológico sobre práticas homoeróticas entre homens em São Paulo. Cadernos Pagu (28), Campinas-SP, Núcleo de Estudos de Gênero-Pagu/Unicamp, 2007, pp.175-206.

Bueno, Alexei. Antologia Pornográfica. De Gregório de Mattos a Glauco Mattoso. Rio de Janeiro, Nova Fronteira, 2004.

BUTLER, Judith. O Parentesco é Sempre Tido como Heterossexual? Cadernos Pagu (21), Campinas-SP, Núcleo de Estudos de GêneroPagu/Unicamp, 2003, pp.219-260.

CARRARA, Sérgio \& SimÕES, Julio. Sexualidade, Cultura e Política: A Trajetória da Identidade Homossexual Masculina na Antropologia 
Brasileira. Cadernos Pagu (28), Campinas-SP, Núcleo de Estudos de Gênero-Pagu/Unicamp, 2007, pp.65-99.

Collins, Patricia Hill. Black Sexual Politics. African Americans, Gender and The New Racism. New York and London, Routledge, 2005.

CORRÊA, Mariza. "Sobre a Invenção da Mulata". Cadernos Pagu (6-7), Campinas-SP, Núcleo de Estudos de Gênero-Pagu/Unicamp, 1996, pp.35-50.

DEBORD, Guy. A Sociedade do Espetáculo. Comentários sobre a Sociedade do Espetáculo. Rio de Janeiro, Contraponto, 1998.

Deleuze, Gilles \& GuatTARI, Félix. Mil Platôs. Capitalismo e Esquizofrenia, vol. 1. São Paulo, Editora 34, 1996.

DíAz-BeníteZ, María Elvira. Nas Redes do Sexo. Os Bastidores do Pornô Brasileiro. Rio de Janeiro, Zahar, 2010.

. Dark Room aqui: Um Ritual de Escuridão e Silêncio. Cadernos de Campo n 16, São Paulo, 2007, pp.93-112.

DIJK, Teun. A. van. Racismo e Discurso na América Latina. São Paulo, Editora Contexto, 2008.

FERNÁNDEZ-DÁVILA, Percy et alii. Construção Social da Sexualidade em Dois Grupos de Homens que Fazem Sexo com Homens(HSH) de Bairros Pobres de Duas Cidades do Peru. Sexualidades, $n^{\circ} 1$. New York, Latin American/Caribbean Regional Editorial Board of the International Resource Network, 2007. Disponível em: $<$ http://www.irnweb.org/assets/journals/cc19ae0cbd5cbeca3bab21e62 2fafee6.pdf $>$.

FIGARI, Carlos.@as Outr@s Cariocas. Interpelações, Experiênciase Identidades Homoeróticas no Rio de Janeiro, Séculos XVII ao XX. Belo Horizonte/Rio de Janeiro, Editora UFMG/IUPERJ, 2007.

Foucault, Michel. As Palauras e as Coisas. São Paulo, Martins Fontes, 1967.

FRANKENBERG, Ruth. A Miragem de Uma Branquidade Não-Marcada. In: WARE, Vron. (org.) Branquidade. Identidade Branca $e$ Multiculturalismo. Rio de Janeiro, Garamond/AFRO, 2004, pp.283-306. 
Representações raciais na pornografia gay

FreYRE, Gilberto. Casa Grande \& Senzala. Rio de Janeiro, Record, 1992. [1933]

. Sobrados e Mucambos. Decadência do Patriarcado Rural e Desenvolvimento do Urbano. Editora Record, 2000. [1936]

FRY, Peter. Da Hierarquia à Igualdade: A Construção Histórica da Homossexualidade no Brasil. In: FRY, Peter. Pra Inglês Ver. Zahar Editores, Rio de Janeiro, 1982.

GIRALDO, Fernando Urrea \& QUíLEZ, Pedro Quintín. Modelos y Fisuras de la Masculinidad entre jóvenes negros de sectores populares en la ciudad de Cali. In: GIRALDO, Fernando Urrea \& QUílEZ, Pedro Quintín. Relaciones Interraciales, Sociabilidades Masculinas Juveniles y Segregación Laboral de la Población Afrocolombiana en Cali. Documentos de Trabajo 49. Cidse. Universidad Del Valle, Cali, 2000, pp.36-53.

GIRALDO, Fernando Urrea, ARIAS, Waldor Botero \& REYES, José Ignacio. Tensiones en La Construcción de identidades de Hombres Negros Homosexuales en Cali. 2007. Manuscrito.

GoldenBERG, Miriam. (org.) Nu \& vestido. Dez Antropólogos revelam a cultura do corpo carioca. Rio de Janeiro, Record, 2002.

HENDERSON, Alex. Company Profile: AEBN's Empire Still Growing. XBIZ.COM. Disponível em: <http://www.xbiz.com/articles/135346> Acesso 25/09/2011.

HONNEF, Klaus. Andy Warhol. 1928-1987. A Comercialização da Arte. Taschen, Lisboa, 1992.

HoOKS, Bell. We Real Cool. Black Men and Masculinity. New York, Routledge, 2004.

JAMESON, Fredric. Postmodernism, or The Cultural Logic of Late Capitalism. New Left Review, ${ }^{\circ}$ 146, London, New Left Review,, 1984, pp.53-93.

MATOS, Gregório de. Antologia (Seleção e Notas de Higino de Barros). Porto Alegre, L\&PM, 2006.

MerCer, K. \& Julian, I. Race, Sexual Politics and Black Masculinity: A Dossier. In: MerCer, K.; Julian, I.; ChAPMAN R. \& RUTHERFORD, J. 
(eds.) Male Order. Unwraping Masculinity. London, Lawrence \& Wishart, 1988, pp.97-164.

MiLleR-Young, Mireille. Hip-Hop Honeys and Da Hustlaz Black Sexualities in the New Hip-Hop Pornography. Meridians: feminism, race, transnationalism, Smith College, Northampton, vol. $8, \mathrm{n}^{\circ} 1$, 2008, pp.261-292.

MISKOLCI, Richard. O Armário Ampliado. Notas sobre sociabilidade homoerótica na era da Internet. Gênero, vol. 9, n 2. Niterói, 2009, pp.171-190.

Do Desvio Às Diferenças. Teoria \& Pesquisa 47, Goiânia, UFG, jul/dez de 2005, pp.9-41.

MORAES, Eliane Robert. Inventário do Abismo. In: Marquês de Sade. Os 120 de Sodoma ou A Escola da Libertinagem. São Paulo, Editora Iluminuras, 2008, pp.9-14. [Trad. Alain François]

MoutinHO, Laura. Razão, “Cor” e Desejo. São Paulo, Editora UNESP, 2004.

OMI, Michael \& WINANT, Howard. Racial Formation in the United States. New York, Routledge, 1994.

ORTNER, Sherry B. Subjetividade e crítica cultural. Horizontes Antropológicos, n 28, Porto Alegre, UFRGS, jul/dez, 2007, pp.375-405.

PAIXÃO, Marcelo J. P. Desenvolvimento Humano e Relações Raciais. Rio de Janeiro, Coleção Políticas da Cor/Laboratório de Políticas Públicas, DP\&A Editora, 2003.

PARKER, Richard. Abaixo do Equador. Culturas do Desejo, Homossexualidade masculina e comunidade gay no Brasil. Rio de Janeiro, Record, 2002.

A Cultura Sexual no Brasil Contemporâneo. São Paulo, Best Seller, 1991, pp.153-204.

Perlongher, Néstor. O Negócio do Michê. A Prostituição Viril. São Paulo, Brasiliense, 1987.

PETRÔNIO. Satíricon. São Paulo, Cosac Naif, 2008. [Tradução: Cláudio Aquati]. Paulo Leminski]

. Satyricon. São Paulo, Editora Brasiliense, 1985. [Tradução: 
Representações raciais na pornografia gay

PINHO, Osmundo. A "Fiel", a "Amante" e o "Jovem Macho Sedutor": Sujeitos de Gênero na Periferia Racializada. Saúde e Sociedade, 16 (2), São Paulo, Faculdade de Saúde Pública, Universidade de São Paulo, 2007, pp.133-145.

. Racismo e raças. In: SADER, Emir e JINKINGS, Ivana. (orgs.) Latinoamericana. Enciclopédia Contemporânea da América Latina e Caribe. São Paulo, Boitempo Editorial, 2006.

- Etnografias do Brau. Corpo, Masculinidade e Raça na Reafricanização em Salvador. Estudos Feministas, 13(1), Florianópolis-SC, 2005, pp.127-145.

- O Efeito do Sexo: políticas de raça, gênero e miscigenação. Cadernos Pagu (23), Campinas-SP, Núcleo de Estudos de Gênero Pagu/Unicamp, 2004, pp.89-120.

PISCITELlI, Adriana. As Fronteiras da Transgressão: a demanda por brasileiras na indústria do sexo na Espanha. Sexualidad, Salud y Sociedad - Revista Latinoamericana. Rio de Janeiro, CLAM-UERJ, 2009, pp.177-201.

RAPISARDE, Flavio \& ModARELli, Alejandro. Fiestas, Baños y Exilios. Los gays Porteños en la ultima dictadura. Buenos Aires, Editorial Sudamericana, 2001.

RodRIGUES, Jose Carlos. O Negro no Cinema Brasileiro. Rio de Janeiro, Pallas, 2001.

SAHLINS, Marshall. Como Pensam os Nativos. Sobre o Capitão Cook, por exemplo. São Paulo, EDUSP, 2001.

SEDGWICK, Eve Kosofsky. A epistemologia do armário. Cadernos Pagu (28), Campinas-SP, Núcleo de Estudos de Gênero - Pagu/Unicamp, 2007, pp.19-54.

SovIK, Liv. Aqui Ninguém É Branco: Hegemonia Branca e Mídia no Brasil. In: WARE, Vron. (org.) Branquidade. Identidade Branca de Multiculturalismo. Rio de Janeiro, Garamond/AFRO, 2004, pp.363-386.

TREVISAN, João Silvério. Devassos no Paraíso. São Paulo, Editora Maax Limonad, 1986. 
WARE, Vron. O Poder Duradouro da Branquidade: Um Problema a Solucionar. In: WARE, Vron. (org.) Branquidade. Identidade Branca de Multiculturalismo. Rio de Janeiro, Garamond/AFRO, 2004, pp.740.

Young, Robert J. C. Colonial Desire. Hibridity in Theory, Culture and Race. London e New York, Routledge, 2002.

Sites consultados (todos acessados pela última vez em 30 de setembro de 2011)

Adult Entertainment Broadcast Network (AEBN):

http://gay.theater.aebn.net/dispatcher/frontDoor?theaterld =14077

Alexander Pictures: http://alexanderpictures.com/

AMG Brasil: http://www.amgbrasil.com/

BaitBus: http://www.baitbus.com/t5/pps=comein/home

Bel Ami: http://tour.belamionline.com/free.aspx

BiLatin: http://bilatinmen.com/

Blatino Studs: http://blatinostuds.com/

Brazilian Studz: http://www.brazilianstudz.com/

PapiThugz: http://papithugz.com/Papithugz.cfm

Porra, Salvador!: http://porrasalvador.tumblr.com/

ThugHunter: http://www.thughunter.com/home

Urban Dictionary: http://www.urbandictionary.com/ 